\title{
Numerical Study on The Structural Behavior of RC Beams after Exposure to Elevated Temperature
}

\author{
Sajida Kadhem Al-Jasmi ${ }^{a}$,Haitham Al-Thairy ${ }^{a}$ * \\ ${ }^{a}$ Civil Engineering Department, College of Engineering, University of Al-Qadisiyah, Iraq.
}

\begin{tabular}{l} 
A R T I C L E I N F O \\
\hline Article history: \\
Received 11 November 2019 \\
Received in revised form 20 October 2019 \\
Accepted 30 October 2019 \\
\hline Keywords: \\
Numerical model \\
RC beams \\
Elevated temperature \\
ABAQUS \\
Heating rate
\end{tabular}

\begin{abstract}
A B S T R A C T
This paper presents a numerical simulation of the structural response of reinforced concrete (RC) beams under elevated temperature using the commercial finite element package ABAQUS. A numerical model is firstly suggested by selecting the appropriate geometrical and material properties of the RC beam model at elevated temperature. Thereafter, the suggested numerical model was validated against the experimental tests conducted in this study. The validation results in terms of temperatures- time histories; load-mid span deflection of the RC beams have confirmed the accuracy of the suggested numerical model. The validated numerical model was implemented in conducting a parametric study to investigate the effects of two important parameters on the behavior and failure of RC beams under elevated temperature. These parameters are the effect of the high ranges of elevated temperatures; and the effect of heating rate. The parametric study results have revealed that the failure load and the ductility of RC beams under elevated temperature are not considerably influenced by changing the heating rate. It has also been concluded that the ultimate load capacities of RC beams have considerably decreased by $55.49 \%, 74.72 \%$, and $81.31 \%$ comparing with the control RC beam when they exposed to temperature values of $600{ }^{\circ} \mathrm{C}, 700{ }^{\circ} \mathrm{C}$, and $800^{\circ} \mathrm{C}$ respectively. These conclusions may be used in the design of $\mathrm{RC}$ beams subjected to fire induced temperature.
\end{abstract}

(C) 2019 University of Al-Qadisiyah. All rights reserved.

\section{Introduction}

Fire induced temperature is one of the most extreme loading conditions that any concrete building may be prone to during its service life. The elevated temperature may cause significant degradation of the mechanical properties of the concrete leading to progressive collapse and failure of the entire structures. One of the examples is the collapse of the world trade centre (WTC) in 2002 which was mainly caused by the elevated temperature induced from the fire following the explosions. Ever since, the awareness of the engineering community has been raised to the importance of incorporating the effect of elevated temperature in the design procedures of structural members. Therefore, a considerable amount of experimental research studies have been conducted during the past two decades on the effect of elevated temperature on the behaviour of concrete members. However, few numerical studies were published on the RC beams members at fire due to the complexity of the problem which involves highly geometrical and material nonlinearities. For example Yue et al. [1] has carried out numerical simulations to study the fireproof behavior of simply supported RC beams strengthened by stranded mesh and polymer mortar (SMPM) by using the finite element software ABAQUS. The coupled

* Corresponding author. Tel.: +964(0)7832685960.

*Corresponding author email: Haitham.althairy@qu.edu.iq (Haitham Al-Thairy) https://doi.org/10.30772/qjes.v12i4.641

2411-7773/@ 2019 University of Al-Qadisiyah. All rights reserved. 
temperature and displacement analysis is fully considered with thermal and mechanical properties of concrete being adopted according to EC4 [2] and others taken from previous researcher studies. The numerical results have revealed that the coupling of displacement and temperature fields can be reasonably modelled by ABAQUS. In addition, Gao et al [3] presented a three dimensional FE model to predict the thermal and the mechanical behaviour of RC beams at high temperature. A concrete damage plasticity constitutive model in ABAQUS [4] was used to model the mechanical behaviour of concrete. The stress-strain relationship and the thermal properties of steel and concrete at elevated temperature were adopted according to EC2[5] and EC3 [6]. In addition, the concrete reduction factors under elevated temperature were taken according to the experimental tests from previous researcher studies and the reduction factors of steel were taken according to EC3 [6]. The results have shown that the inclusion of steel to concrete interfacial behaviour leads to more accurate predictions of the deflection of RC beams exposed to fire. Also, the numerical study conducted by Ožbolt et al [7] has developed a three dimensional finite element model to study the response of simply supported RC beams made from crushed stone aggregate. ISO 834 [8] standard fire curve was used under elevated temperatures up to $300^{\circ} \mathrm{C}$ followed by mechanical loading. The thermal and mechanical procedure available in ABAQUS was utilized to perform the analysis. The thermal properties of steel and concrete used are taken from EC2 [5] and EC3 [6]. The results indicated that the employed numerical modeling technique can successfully predict the behaviour of the RC beam under fire and followed by mechanical load. Further the used 3D thermo-mechanical model is useful numerical tool for the realistic prediction of the behaviour of RC structures exposed to high temperature. In the same contexts, El-Tayeb et al [9] have carried out a numerical investigation on the response of RC beams and frames under the effect of thermal loads using the FE software ABAQUS. The beams and frames were modelled by accounting the material nonlinearity including cracking behaviour and the gradients of temperature are assumed linear, nonlinear and uniform. The results have indicated that the behaviour of beams and frames is largely deviated depend on the trend of the temperature gradient (i.e. linear or nonlinear). Therefore, the nonlinear gradient of temperature was suggested to be implemented in the analysis.

The above-mentioned research studies have shown that the finite element package ABAQUS has widely been utilized in simulating the behaviour and failure of RC beams at elevated temperature with a very reasonable accuracy. The stress-strain model of concrete under elevated temperature proposed by EC2[5], EC3[6] and EC4 [2] was successfully used to predict the degradation of the concrete strength under high temperature. However, the previous numerical models have not been validated against experimental tests results with different ranges of elevated temperatures and have not been used to conduct comprehensive parametric study. Therefore, the main object of the current study is to develop a more accurate numerical model to simulate the behaviour of RC beams under elevated temperature using the FE software ABAQUS/Standard. In addition, the validated numerical model will be used to conduct a parametric study to investigate the effects of two important parameters on the behaviour and failure of RC beams at elevated temperature. These two parameter have not been be investigated by the previous numerical research studies.

\section{The FE Model of the RC beams}

\subsection{Material modeling}

The concrete damaged plasticity model (CDPM) available in ABAQUS/Standard was used in this study to simulate the behavior of the concrete material under ambient and elevated temperature up to failure. The CDPM uses several parameters to simulate the plastic behavior of concrete. In the present model, some of the required plasticity parameters for RC beams were taken as the default values in ABAQUS. One the other hand, the mathematic constitutive model for the compressive stress-strain relationship of concrete by EC4 [2] was adopted at ambient and elevated temperatures. The values of yielding and crushing strains of concrete at different temperatures were taken according to EC4 [2]. To account for the degradation of the mechanical properties of concrete at elevated temperature, reduction factors of compressive strength were obtained from the experimental tests conducted in this study (see Fig. 1).

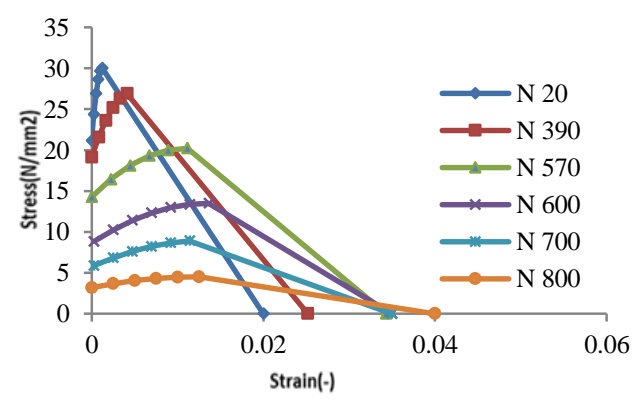

Figure 1. Stress - strain relationships of $\mathrm{RC}$ beams at various temperatures

The tension stiffening of concrete at ambient and elevated temperature was defined in terms of the fracture energy (Gf) available in ABAQUS [10, 11] as show in Fig. 2. According to CEB-FIP Model [12], the value of Gf can be obtained as a function of the maximum aggregate size $\left(D_{\max }\right)$ and the required concrete strength as presented in Table 1 . On the other hand the reduction factors of tensile strengths of concrete at elevated temperature suggested by EC2 [5] was used in the tension stiffening model to account for the effect of the elevated temperature.

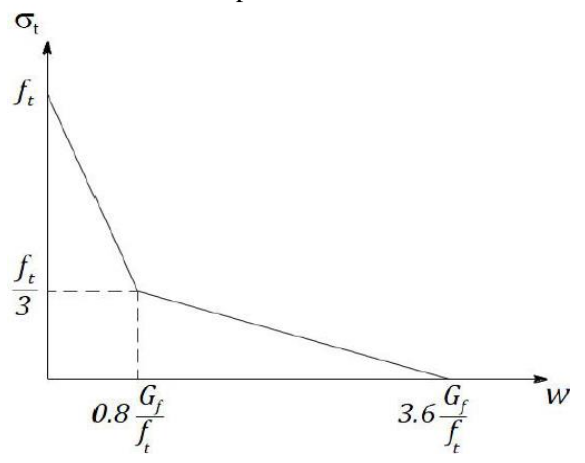

Figure 2: Bilinear softening tension used for NWC [10, 11]. 
Table 1: Values of $\mathbf{G}_{\mathrm{f}}$ for different aggregate sizes and concrete strengths according to [10]

\begin{tabular}{|c|c|c|c|c|c|c|c|c|}
\hline $\operatorname{Dmax}(\mathbf{m m})$ & $G f($ & & & & & & & \\
\hline & $\mathrm{C} 12$ & $\mathrm{C} 20$ & C30 & $\mathrm{C} 40$ & C50 & C60 & C70 & $\mathrm{C} 80$ \\
\hline 8 & 40 & 50 & 65 & 70 & 85 & 95 & 105 & 115 \\
\hline 16 & 50 & 60 & 75 & 90 & 105 & 115 & 125 & 135 \\
\hline 32 & 60 & 80 & 95 & 115 & 130 & 145 & 160 & 175 \\
\hline
\end{tabular}

One the other hand, the tension damage parameters was used in this study to detect the crack initiation of RC beams at ambient and elevated temperature. The tension damage parameter is calculated from the equation suggested by ABAQUS [5] as follows:

$\mathrm{d}_{\mathrm{t}}=1-\frac{\sigma t}{f c t m}$

Where $\sigma$ is the tension stress of concrete at the stage of analysis where the damage parameter is to be calculated and $f c t m$ is the ultimate tension stress of concrete.

For the reinforcement bars, the mathematic constitutive model of the stress-strain relationship of steel at tension proposed by EC4 [2] for ambient and elevated temperature was used. The yielding stress, modules of elasticity and Poisson's ratio of the steel material at ambient temperature were taken as $414 \mathrm{MPa}, 2 \times 10^{5} \mathrm{Mpa}$, and 0.2 respectively.

\subsection{Geometrical modeling}

The three dimensional eight nodes solid element with reduced integration and hourglass control (C3D8R) in ABAQUS/standard shown in Fig. 3-a was used in this study to model the RC beams, bearing steel plate and supporting steel plates during the structural analysis. While, in the heat transfer analysis, the three dimensional eight- node solid liner heat transfer element (DC3D8) with a temperature degree of freedom was used (see Fig. 3-a). One the other hand, the reinforcing steel bars was modeled by using a three-dimensional two-node linear displacement truss element (T3D2) during the structural analysis while a two-node heat transfer link element (DC1D2) with a temperature degree of freedom was utilized during the heat transfer analysis as shown in Fig. 3-b. Table 2 summary all types of element used in the numerical model of this study.

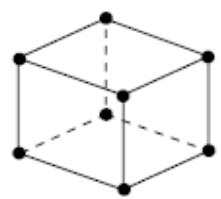

a :C3D8R and DC3D8 elements

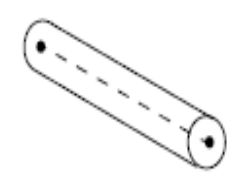

b: T3D2 and DC1D2 elements
Figure 3. Types of elements used in the numerical model

Table 2: Types of elements used in the numerical mode

\begin{tabular}{lll}
\hline Material type & $\begin{array}{l}\text { Structural } \\
\text { analysis }\end{array}$ & $\begin{array}{l}\text { Heat transfer } \\
\text { analysis }\end{array}$ \\
\hline RC beams & C3D8R & DC3D8 \\
Bearing and supporting steel pates & C3D8R & DC3D8 \\
Reinforcing steel & T3D2 & DC1D2 \\
\hline
\end{tabular}

\subsection{Assembly of the numerical model}

Fig. 4 shows the assembly of all parts used in the numerical model of this study including the details of the reinforcement bars. Bearing and supporting steel plates with dimensions of $(150 \times 100 \times 10) \mathrm{mm}$ and $(150 \times 80$ $\times 10) \mathrm{mm}$ (length $\times$ width $\times$ depth) respectively were used to eliminate localizing of stresses at supporting and loading areas. The TIE type of the CONSTRAIN option in ABAQUS was used to tie up theses plates to the $\mathrm{RC}$ beams. The boundary conditions of the beams were modeled to simulate the simply supporting boundary conditions as used in the experimental tests. In addition, the EMBEDDED REIGN type of the CONSTRAIN option in ABAQUS was utilized to set the interaction between the reinforcement steel bars and the concrete beams.

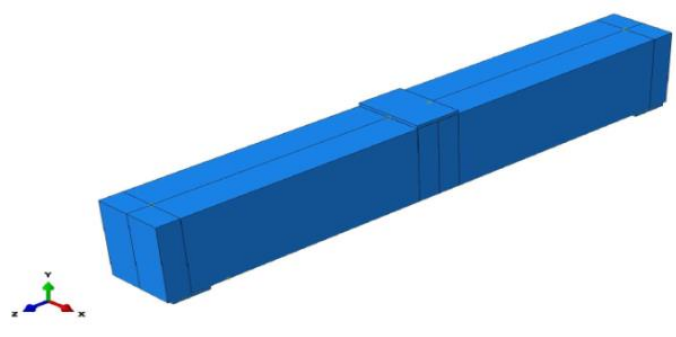

a: RC model in ABAQUS

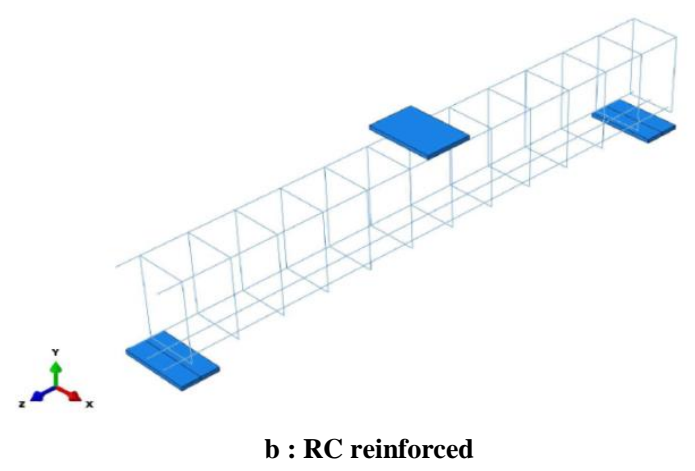

Figure 4: Assemblage of the numerical models

\subsection{Analysis procedure}

The partially coupled thermal and mechanical analysis in ABAQUS/Standards was used in the present study to analyze the RC beams under elevated temperature followed by static point load. In this analysis procedure, the heat transfer analysis is carried out to predict the temperature distribution over the RC beams while mechanical analysis was carried out to determine the stress, strain and displacement distributions at the beam up to failure. The main features of each phase of analysis are described as follows:

\subsection{Heat transfer analysis}

In this analysis, the RC beams were heated up to the intended degree of temperature which is applied over the whole beam as a boundary condition following the temperature- time histories obtained from the corresponding experimental tests conducted in this study as shown in Fig. 5. The thermal expansion, specific heat and thermal conductivity of concrete and the steel were all defined as a function of temperature in the material properties of the numerical model using values supposed by the EC4[3]. 


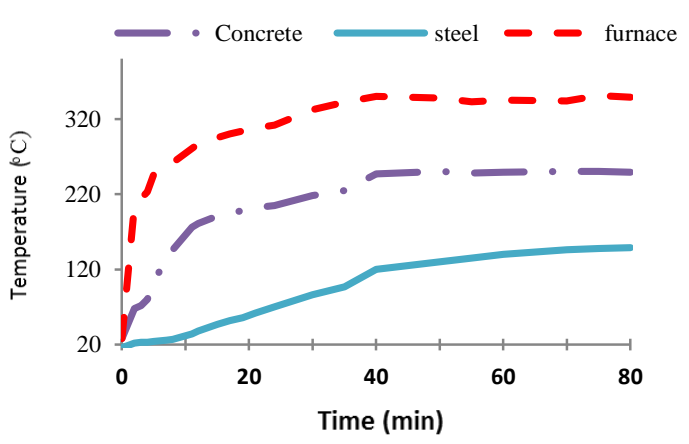

$\mathrm{a}: \mathrm{N} 250^{\circ} \mathrm{c}$

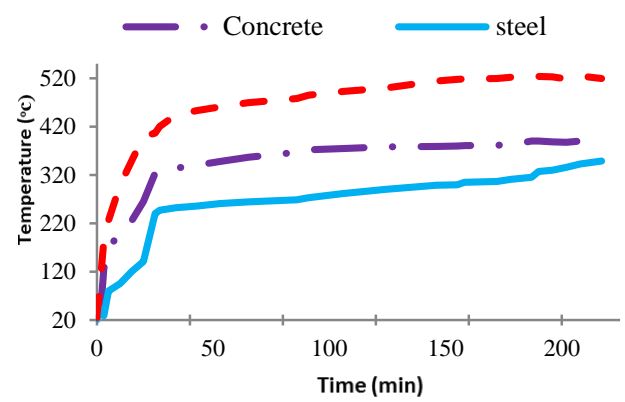

$\mathrm{b}: \mathbf{N 3 9 0}{ }^{\circ} \mathrm{C}$

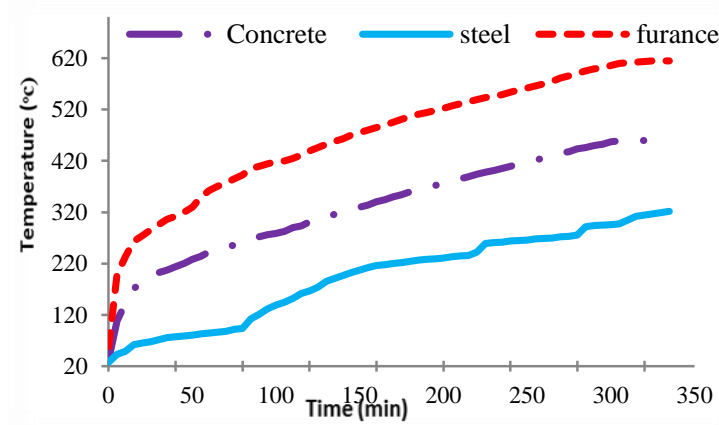

$\mathrm{c}: \mathbf{N 4 6 0} 0^{\circ} \mathrm{C}$

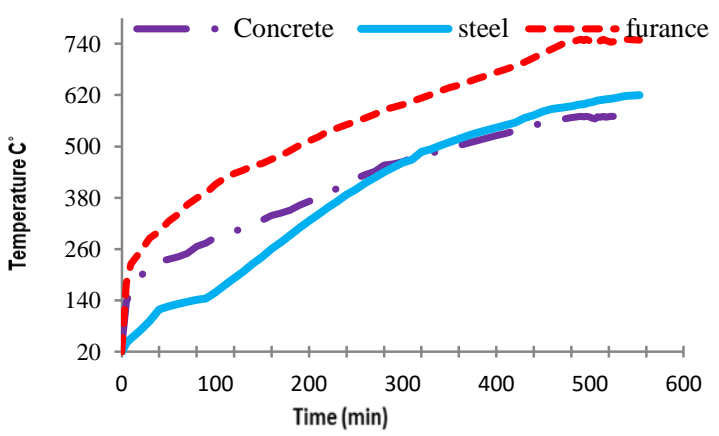

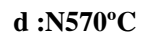

Figure 5: Temperature-time histories at furnace, $\mathrm{RC}$ beam pecimens and the steel bars used in the present study

\subsection{Structural analysis}

The structural analysis was carried out after heat transfer analysis to predict the structural behavior of RC beams after temperature exposure. The distribution of temperature over the RC beams was restored from the heat transfer analysis as an initial step of the RC beams using the PREDEFINED FIELDS option in ABAQUS. A displacement controlled structural analysis was carried out by applying a lateral displacement as a boundary condition at the center of RC beams.

\section{Validation of the numerical model.}

To ensure the reliability of the developed numerical model, experimental tests were carried out in this study on RC beams subjected to elevated temperature followed by concentrated static load at the beam's mid-span .The numerical simulation results obtained from the suggested model will be compared with the experimental tests results. The section below describes the experimental tests used in the validation exercises.

\subsection{Experimental tests}

Five RC beams with cross sectional dimensions of $150 \mathrm{~mm} \times 240 \mathrm{~mm}$ (width $\times$ height) and total length of $1250 \mathrm{~mm}$ were cast, cured, heated and tested in the present study. The average values of compressive and tensile strengths of the concrete used in all RC beams specimens are $31.45 \mathrm{MPa}$ and $2.875 \mathrm{MPa}$ respectively. The geometrical and reinforcing details of RC concrete beams are shown in Fig. 6. The RC beams were designed to resist lateral concentrated load at beams mid-span of $150 \mathrm{kN}$ according to ACI 318-2014 [13]. Four RC beams were tested after exposing to four different elevated temperatures which are $250^{\circ} \mathrm{C}, 390^{\circ} \mathrm{C}, 460^{\circ} \mathrm{C}$, and $570^{\circ} \mathrm{C}$ while one beam was tested under ambient temperature (i.e. $20^{\circ} \mathrm{C}$ ) and it was considered as the control beam. For each of the four heated RC beams, the temperature was maintained constant for about half an hour when it reaches the target value. An electric furnace with dimensions of $1300 \mathrm{~mm}$ (length) $\times 330 \mathrm{~mm}$ (depth) and $290 \mathrm{~mm}$ (height) and maximum temperature of $900^{\circ} \mathrm{C}$ was designed, manufactured and calibrated in this study and used to heat up the RC beam specimens as shown in Fig. 7. The average heating rate of the furnace was controlled to be $10^{\circ} \mathrm{C} / \mathrm{min}$ and remained in furnace for about half hour, then, the RC beams were naturally cooled down to ambient temperature .
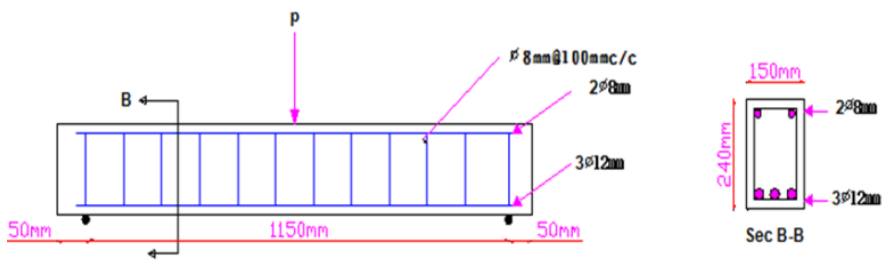

Figure 6: Dimensions and reinforcement details of $\mathrm{RC}$ beams 


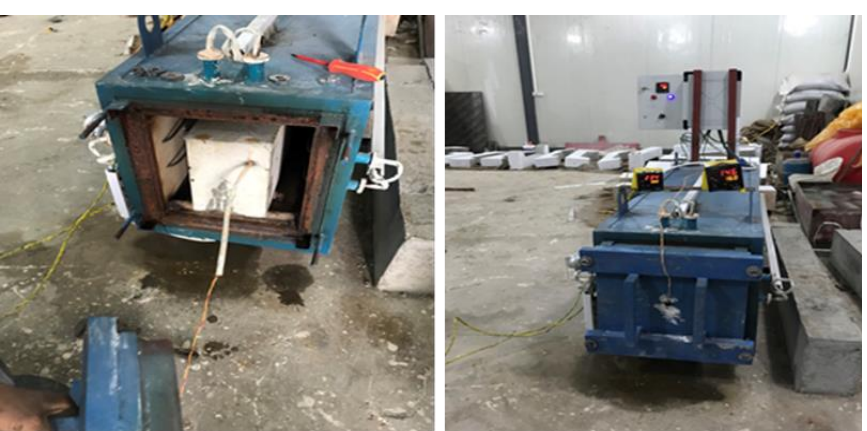

Figure 7: The electric furnace setup

All RC beams were subjected to a monotonically increased concentrated static load at the beams mid span up to failure using the universal testing machine available at the College Engineering/University of Al-Qadisiyah/. Load cell and linear variable displacement transformer (LVDT) were used to measure and capture load- lateral displacement relationships of the RC beam under different elevated temperatures. The ends support conditions of the RC beam specimens were arranged in the tests to simulate the simply supported condition by allowing the ends to move in axial directions and to rotate in the axis perpendicular to the beam plane.

\subsection{Validation of the numerical model against thermal tests}

Fig. 8 compares the temperature-time histories at the reinforcement steel bars for all heated RC beam specimens between the numerical simulation results and the experimental tests results. Reasonable correlation can be noted between the two sets of results, particularly the correlation between the maximum values of the temperature transferred from the concrete to the steel rebar. It can also be noticed from Figs. (8-a) to (8-d) that the percentage of difference between experimental and numerical results in the peak temperatures at the reinforcement steel bars is about (3.5$6.1) \%$ for all the heated RC beams.

\subsection{Validation the numerical model against the structural tests}

Fig. 9 and Table 3 compare the load-deflection relationships and the failure load respectively of RC beams between the numerical simulation results and the experimental test results. Excellent agreement can be seen between the two sets of results. It can also be seen from Table 3 that the maximum absolute error between the numerical and experimental results does not exceed $7 \%$. This agreement confirms that the suggested numerical model with the associated geometrical and material modeling parameters can reasonably predict the response of the $\mathrm{RC}$ beam at elevated temperature up to failure.

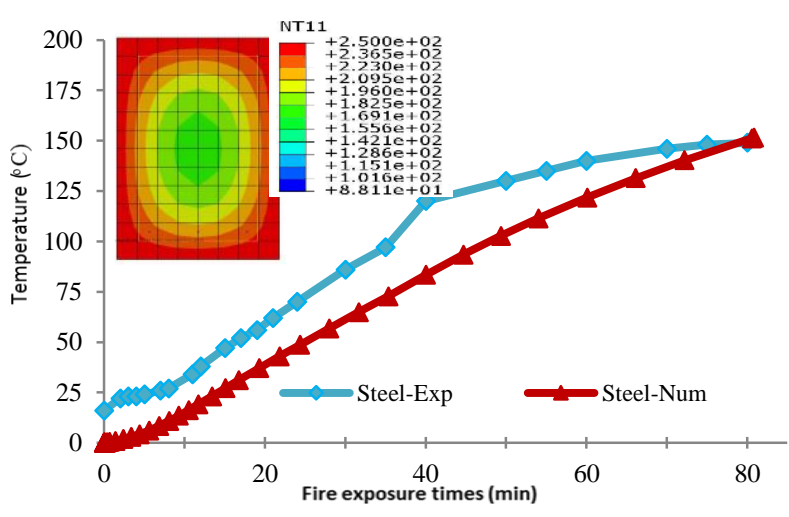

a: $250^{\circ} \mathrm{C}$

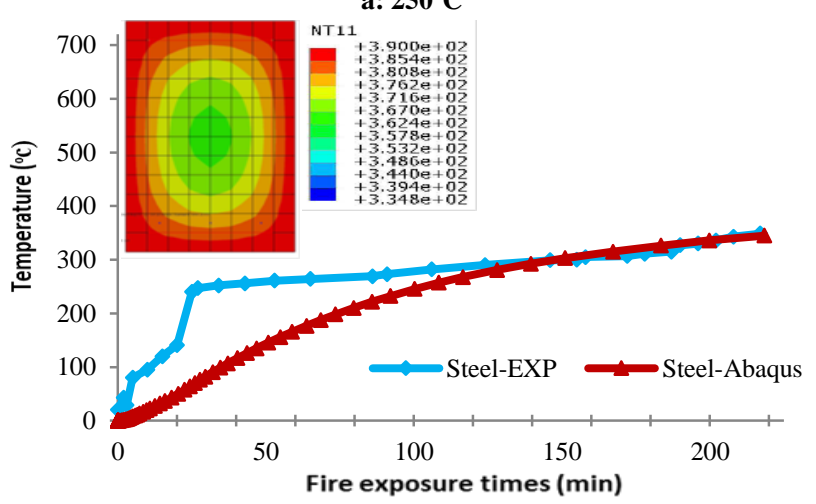

b: $390^{\circ} \mathrm{C}$

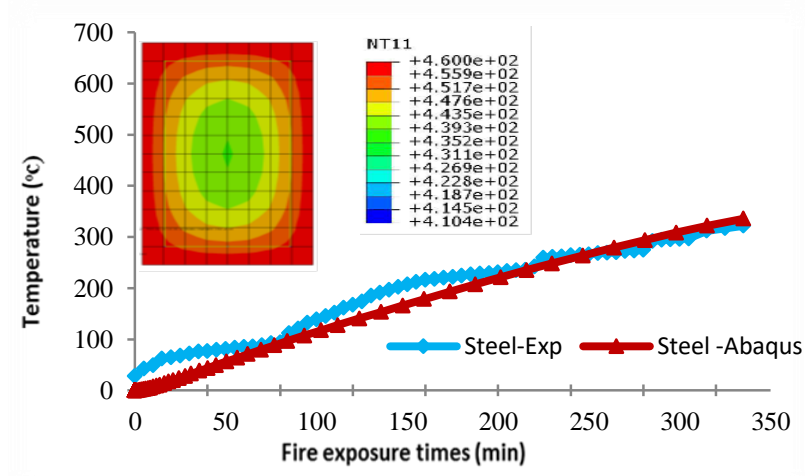

c: $460^{\circ} \mathrm{C}$

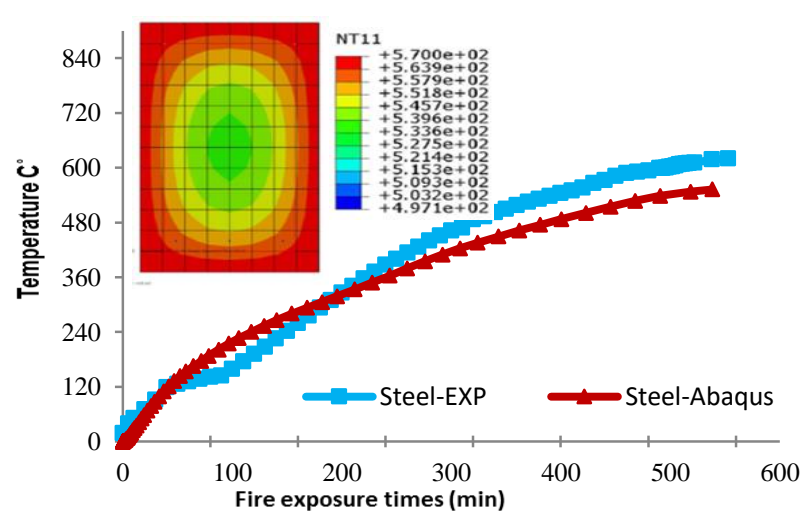

d: $570^{\circ} \mathrm{C}$

Figure 8. Comparison of temperature-time histories at the reinforcement steel bars between ABAQUS and the experimental test results RC beams. 


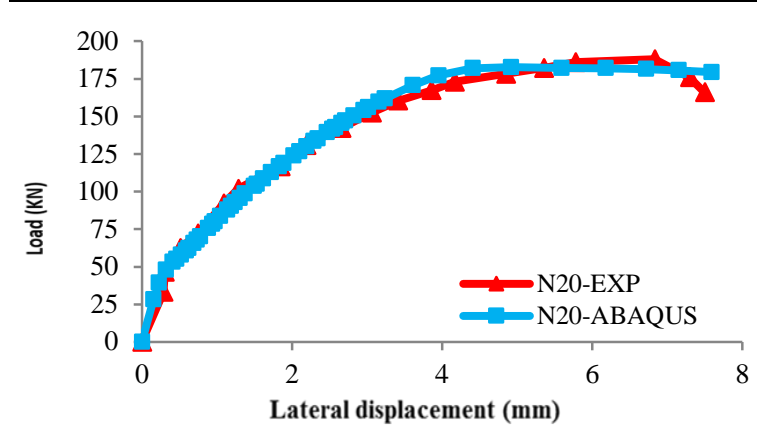

a: $20^{\circ} \mathrm{C}$

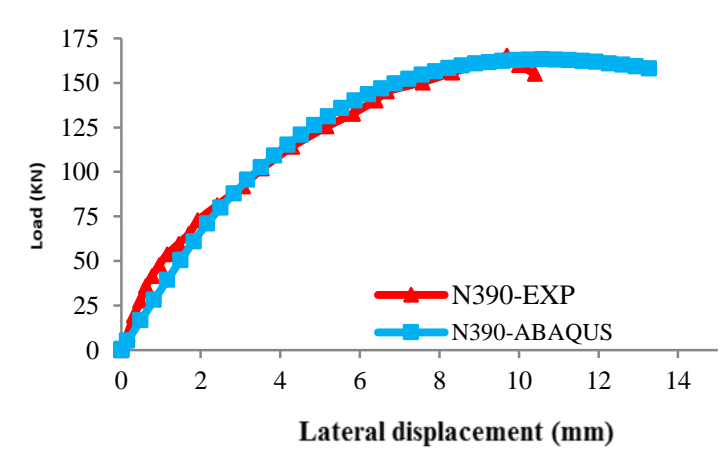

b: $390^{\circ} \mathrm{C}$

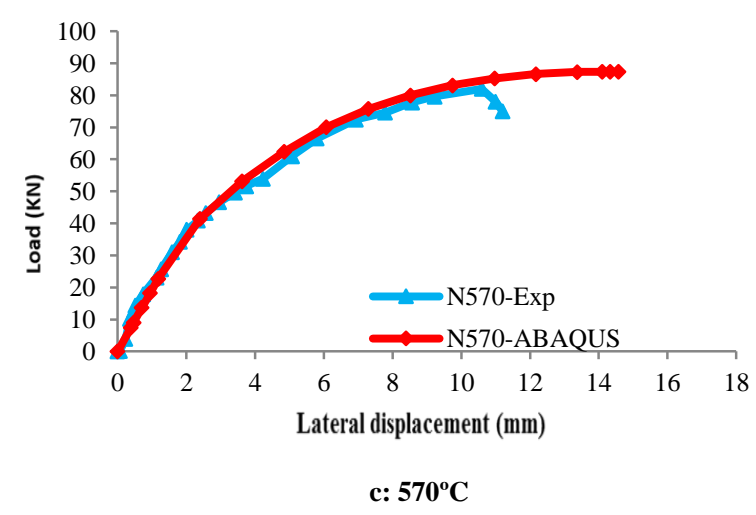

Figure 9: Comparison of load- displacement relationships of RC under different elevated temperature between ABAQUS and the experimental test results.

Table 3. Compariosn of the ultimate (failur) load-temperature relationship of $\mathrm{RC}$ beams between $\mathrm{ABAQUS}$ and experimemental results

\begin{tabular}{lll}
\hline Type of beam & Failure load (kN)-ABAQUS & $\boldsymbol{\mu}=\mathbf{D}_{\max } / \mathbf{D}_{\mathbf{y}}$ \\
\hline $\mathrm{N} 20^{\circ} \mathrm{C}$ & 182 & 3.4 \\
$\mathrm{~N} 600^{\circ} \mathrm{C}$ & 81 & 3.1 \\
$\mathrm{~N} 700^{\circ} \mathrm{C}$ & 46 & 3.2 \\
$\mathrm{~N} 800^{\circ} \mathrm{C}$ & 34 & 2.3 \\
\hline
\end{tabular}

\section{Parametric study}

The validated numerical mode was used to conduct a parametric study to investigate the effects of two important parameters that are not investigated in the experimental test due to the limited laboratory resources. These parameters include the following:

1. Effect of the high ranges of elevated temperatures

2. Effect of heating rate

\subsection{Effect of the high ranges of elevated temperatures}

To investigate the effect of applying high ranges of elevated temperature on the response of RC beams, numerical simulations were carried out on RC beams subjected to three different elevated temperatures namely: $600^{\circ} \mathrm{C}, 700^{\circ} \mathrm{C}$, and $800^{\circ} \mathrm{C}$. Fig. 10 and Table 4 show the numerical simulation results.

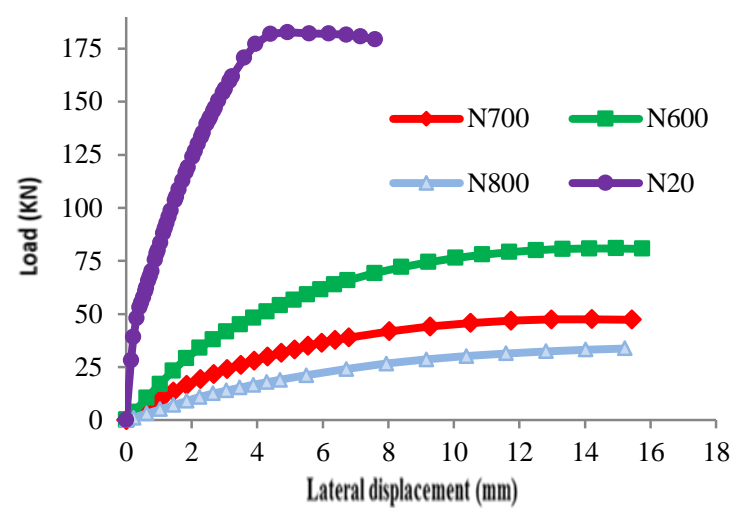

Figure 10: Effect of high elevated temperatures on the behavior of RC beams.

It can be observed from Fig. 10 that when the temperature increases, the ultimate load values of RC beams decreases. The ultimate load capacity of RC beams (see Fig. 10) has considerably decreased by $55.49 \%, 74.72 \%$, and $81.31 \%$ compared to the control beam when exposure to temperature values of $600{ }^{\circ} \mathrm{C}, 700{ }^{\circ} \mathrm{C}$, and $800^{\circ} \mathrm{C}$ respectively. In addition, the calculated values of ductility index of RC beams for different temperature were tabulated in Table 4. The results in Table 4 demonstrates that the values of ductility index decreases by $8.8 \%, 5.88 \%$, and $32.35 \%$ compared to the control beam when they exposed to temperature values of $600{ }^{\circ} \mathrm{C}, 700{ }^{\circ} \mathrm{C}$, and $800^{\circ} \mathrm{C}$ respectively. This reduction in the ductility can be attributed to the degradation in the mechanical properties of both concrete and steel.

Table 4. Ductility index values of $\mathrm{RC}$ beam specimens.

\begin{tabular}{llll}
\hline $\begin{array}{l}\text { Type of } \\
\text { beam }\end{array}$ & $\begin{array}{l}\text { Failure load } \\
\text { (kN)- } \\
\text { ABAQUS }\end{array}$ & $\begin{array}{l}\text { Failure load (kN)- } \\
\text { Experimental }\end{array}$ & $\begin{array}{l}\text { Maximum } \\
\text { Absolute Error } \\
\text { (MAE)\% }\end{array}$ \\
\hline $\mathrm{N} \mathrm{20} 0^{\circ} \mathrm{C}$ & 182 & 188 & 3.19 \\
$\mathrm{~N} 390^{\circ} \mathrm{C}$ & 163 & 165 & 1.21 \\
$\mathrm{~N} 570^{\circ} \mathrm{C}$ & 87 & 82 & 6.09 \\
\hline
\end{tabular}




\subsection{Effect of heating rate}

Fig. 11 shows the heating rates considered in this study. The first curve represents the actual heating rate corresponding to the elevated temperature of $570{ }^{\circ} \mathrm{C}$ based on the experimental tests. The other three curves are the assumed heating rates obtained by decreasing the heating times to half the actual experimental time and increasing the heating time by two and three times the actual experimental times respectively.

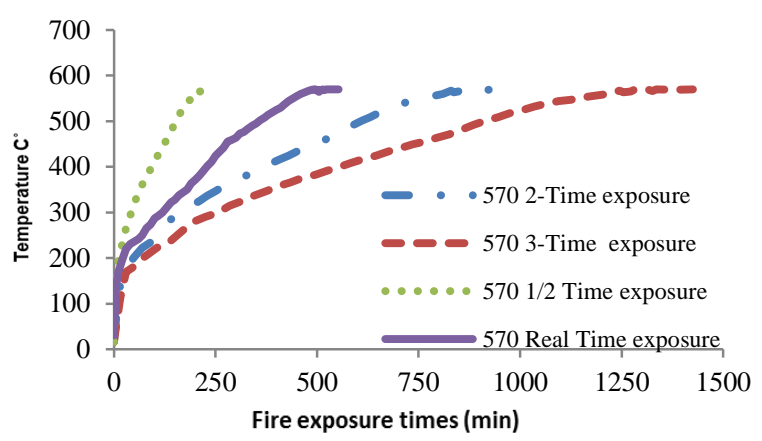

Figure 11: Heating rates used in the parametric study $\left(\mathrm{T}=570^{\circ} \mathrm{C}\right)^{-}$

Fig. 12 and Table 5 show the load-displacement behavior of the RC beams under different heating rates with a comparison with the results obtained from the experimental tests. It can be noted from Fig. 12 that values of failure load are not considerably influenced by the change in times of temperature exposure. The ultimate load capacity has been decreased by $5.74 \%$ and $1.14 \%$ when heating times are two times and three times the experimental exposure time respectively (see Fig. 12). When the exposure time is divided to half the experimental exposure time, the values of failure load increased by $3.33 \%$ for the RC beam compared to the RC beams under actual experimental time with reducing values of vertical displacement. Further, as we can see from Table 5, values of ductility index decreased by $8.9 \%$, and $11.76 \%$ when heating times are two times and three times the experimental exposure time respectively. It is noted that the ductility index for RC beams was not largely affected by the change in times of temperature exposure and even it got a slight increase by $4.95 \%$ when the actual times of temperature exposure of RC beams is divided by half. This is because the calculation of ductility index depends only on displacement of the beams. The RC beams exhibit a steeper and more linear behaviour in the ascending part of the load-displacement curve after the exposure to elevated temperature and then a quickly descended prior to failure.

Table 5. Ductility index values of $\mathrm{RC}$ beam specimens.

\begin{tabular}{lll}
\hline Type of beam & $\begin{array}{l}\text { Failure load }(\mathbf{k N})- \\
\text { ABAQUS }\end{array}$ & $\begin{array}{l}\boldsymbol{\mu} \\
=\mathbf{D}_{\text {max }} / \mathbf{D}_{\mathbf{y}}\end{array}$ \\
\hline N $570^{\circ} \mathrm{C}-$ Full time exposure & 87 & 3.23 \\
N $570^{\circ} \mathrm{C}-$ Half time exposure & 90 & 3.39 \\
N $570^{\circ} \mathrm{C}-2$ time exposure & 82 & 2.94 \\
N $570^{\circ} \mathrm{C}-3$ times exposure & 86 & 2.85 \\
time & & \\
\hline
\end{tabular}

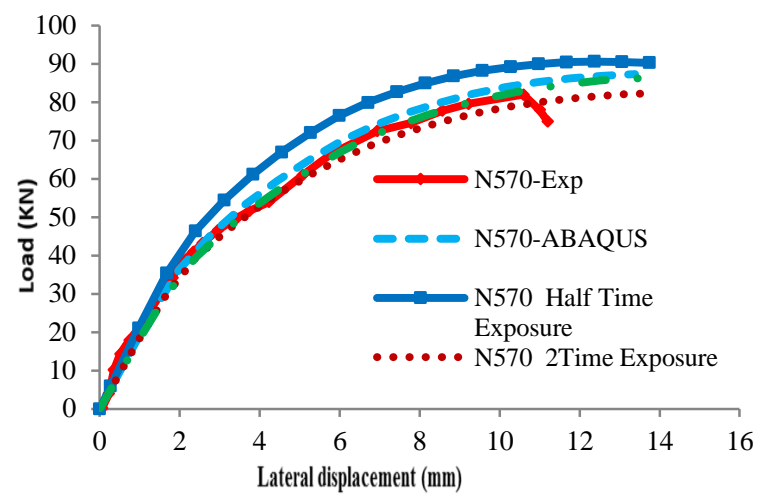

Figure 12: Comparison of the load-displacement responses of WRC beams under different heating rates

\section{Conclusions}

This study has suggested and validated a numerical model to simulate the behaviour and failure of $\mathrm{RC}$ beams under different elevated temperatures using the finite element package ABAQUS. A numerical model was firstly developed and validated against the results of the experimental tests conducted in this study. Afterward, the validated numerical model was utilized to investigate the effect of two important parameters on the response and failure load of RC beam subjected to elevated temperature followed by static load. From the validation and parametric study results, the following conclusions can be extracted:

1. The finite element package ABAQUS can reasonably predict the failure and the response RC beams under elevated temperature if suitable geometrical and thermal dependent material properties are adopted. The results have indicated that using the material model with the associated reduction factors of compressive strength suggested by EC4 [3] is suitable to represent the degradation of the concrete due to elevated temperatures.

2. The failure load of RC beams is not considerably influenced by changing the heating rate. The ultimate load capacity has been decreased by $1.14 \%$ and $5.74 \%$ when heating times are two times and three times the experimental exposure time respectively Results have also shown that under the same value of temperature, the vertical displacement values for RC beams have increased when the heating rate was increased. One the other hand, when the exposure time is divided to half the experimental exposure time, the values of failure load of the RC beam increased by $3.33 \%$ compared to the $\mathrm{RC}$ beams under experimental time with reducing the values of vertical displacement. Moreover, results have revealed that the ductility of the RC beam decreased when heating times are increases.

3. The numerical results have revealed that the ultimate load capacity RC beams has considerably decreased by $55.49 \%$, $74.72 \%$, and $81.31 \%$ compared to the control beam when they exposed to temperature values of $600{ }^{\circ} \mathrm{C}, 700{ }^{\circ} \mathrm{C}$, and $800^{\circ} \mathrm{C}$ respectively. 


\section{REFERENCE}

[1] Yue, M.G. , Yao, Q.L., Wang, Y.Y. and Li, H.N.(2008). Numerical Simulation on The Fire Proof Behavior of RC Beams with Strand Mesh and Polymer Mortar- The 14World Conference on Earthquake Engineering October 12-17, 2008, Beijing, China, IPP. 1-6

[2] Euro code 4. (2005). Design of composite steel and concrete structures-'EN 1994.Part 1-2: General rules - Structural fire design, (August), pp. 1-109

[3] Gao, W. Y., Chen, G. M., Teng, G. J.,\& Dai, J. G. (2013) 'Finite element modeling of reinforced concrete beams exposed to fire'. Elsevier Ltd, 52, pp. 488-501. doi: 10.1016/j.engstruct.2013.03.017.

[4] ABAQUS Standard user"s manual, Volumes I-III, Version 6.8. Pawtucket (America): Hibbitt, Karlsson \& Sorensen, Inc.; 2008.

[5] Eurocode 2 (2004) 'Design of concrete structures'Part 1-2: General rules Structural fire design Euro code SS-EN-1992-1-1:2008, 3(July).

[6] Eurocode 3 (2011) ' Design of steel structures' Part 1-1: General rules and rules for buildings', EN-1993-1-1:2011. March 2009

[7] Oz`bolt, J., Bošnjak, J., Periškic, A. S. (2013) '3D numerical analysis of reinforced concrete beams exposed to elevated temperature', Engineering Structures (2013), pp. 1-9.

[8] ISO 834-1, Fire Resistance Tests-Elements of Building Construction. Part 1:General Requirement, International Organization for Standardization, Geneva, Switzerland, 1999.

[9]El-Tayeb, E. H., El-Metwally, S. E., Askar, H. S., \& Yousef, A. M. (2017). Thermal analysis of reinforced concrete beams and frames, HBRC Journal. 132 Housing and Building National Research Center, 13(1), pp. 8-24.

[10] Hillerborg, A., (1985), "The theoretical basis of a Method to determine the fracture energy Gf of concrete", Materials and Structures, Vol. 18, No. 4, pp. 291-296 [19] Hibbitt, Karlsson, Sorensen, 2010. "ABAQUS User"s Manual”. Pawtucket, 6th Edition

[11] Cornelissen, H., Hordijk, D., Reinhardt, H., (1986), "Experimental determination of crack softening characteristics of normal weight and lightweight concrete". Heron, Vol. 31, No. 2, Delft, The Netherlands [12] CEB-FIP Model Code 90, "concrete Structures" (1993). Concrete Structures". Thomas Telford Publishing. [13] ACI Committee. (2014). Building Code Requirements for Structure

Concrete and Commentary ACI 318M. American Concrete Institute, Michigan. 